\title{
Cross-Talk between Vascular Endothelial Growth Factor and Matrix Metalloproteinases in the Induction of Neovascularization in Vivo
}

\author{
Quteba Ebrahem, ${ }^{*}$ Shyam S. Chaurasia, ${ }^{*}$ \\ Amit Vasanji, ${ }^{\dagger}$ Jian Hua Qi, ${ }^{*}$ Phillip A. Klenotic, ${ }^{*}$ \\ Alecia Cutler, ${ }^{*}$ Kewal Asosingh, ${ }^{\ddagger}$ Serpil Erzurum, ${ }^{\neq}$ \\ and Bela Anand-Apte* \\ From the Department of Ophthalmology, Cole Eye Institute, \\ Cleveland Clinic Lerner College of Medicine, Cleveland; and the \\ Departments of Biomedical Engineering, ${ }^{\dagger}$ and Patbobiology, ${ }^{\dagger}$ \\ Lerner Research Institute, Cleveland Clinic, Cleveland, Obio
}

Matrix metalloproteinases (MMPs), a specialized group of enzymes capable of proteolytically degrading extracellular matrix proteins, have been postulated to play an important role in angiogenesis. It has been suggested that MMPs can regulate neovascularization using mechanisms other than simple remodeling of the capillary basement membrane. To determine the interplay between vascular endothelial growth factor (VEGF) and MMPs, we investigated the induction of angiogenesis by recombinant active MMPs and VEGF in vivo. Using a rat corneal micropocket in vivo angiogenesis assay, we observed that the active form of MMP-9 could induce neovascularization in vivo when compared with the pro- form of the enzyme as a control. This angiogenic response could be inhibited by neutralizing VEGF antibody, which suggests that MMPs acts upstream of VEGF. Additional in vitro studies using extracellular matrix loaded with radiolabeled VEGF determined that active MMPs can enzymatically release sequestered VEGF. Interestingly, in vivo angiogenesis induced by VEGF could be inhibited by MMP inhibitors, indicating that MMPs also act downstream of VEGF. In addition, inflammation plays an important role in the induction of angiogenesis mediated by both VEGF and MMPs. Our results suggest that MMPs act both upstream and downstream of VEGF and imply that potential combination therapies of VEGF and MMP inhibitors may be a useful therapeutic approach in diseases of pathological neovascularization. (Am J Pathol 2010, 176:496-503; DOI: 10.2353/ajpath.2010.080642)
Angiogenesis, the sprouting of new capillaries from preexisting blood vessels, is a multistep process requiring the degradation of the basement membrane, endothelial cell migration, endothelial cell proliferation, and capillary tube formation. Precise spatial and temporal regulation of extracellular proteolytic activity mediated by matrix-degrading enzymes appears to be important in the initial process of endothelial cell invasion into the extracellular matrix (ECM). ${ }^{1}$ Three families of enzymes, the matrix metalloproteinases (MMPs), a disintegrin and metalloprotease domain (ADAM) family, and a disintegrin-like and metalloprotease domain (reprolysin type) with thrombospondin type I repeats (ADAMTS) family ${ }^{2}$ mediate the proteolysis of ECM proteins.

MMPs (eg, collagenases, gelatinases, and stromelysins) are a family of zinc binding, $\mathrm{Ca}^{2+}$-dependent neutral endopeptidases that can act together or in concert with other enzymes to degrade most components of the ECM. ${ }^{3,4}$ These enzymes have been implicated in invasive cell behavior and recent studies have indicated that MMPs play an important role in the regulation of angiogenesis. ${ }^{5-8}$ Mice deficient in MMP-2 (gelatinase A), MMP-9 (gelatinase $\mathrm{B}$ ), or MMP-14 exhibit reduced angiogenesis in vivo, $^{9-11}$ and members of the tissue inhibitor of metalloproteinase family are potent angiogenesis inhibitors. ${ }^{12,13}$

A number of mechanisms by which remodeling of the ECM by MMPs and other proteases can regulate angiogenesis have been proposed.6,14,15 Since MMPs degrade proteins in the ECM, their primary function has been considered to be the breakdown of the capillary basement membrane to allow the migration of endothelial cells into the surrounding matrix. More recently, additional ectodomain shedding and release of matrix-bound

Supported in part by National Institutes of Health grants EY016490, CA106415, and EY015638 (to B.A.-A.); a Foundation Fighting Blindness Center grant (to B.A.-A.); an American Heart Association Grant in Aid (to B.A.-A.); Ohio BRTT 05-29 (to B.A.-A.); and Research to Prevent Blindness Challenge Grant and Lew Wasserman Award (to B.A.-A.)

Accepted for publication September 8, 2009

Address reprint requests to Bela Anand-Apte, MBBS, Ph.D., Department of Ophthalmology, Cole Eye Institute, Cleveland Clinic Lerner College of Medicine, 9500 Euclid Avenue, Cleveland, OH 44195. E-mail: anandab@ccf.org. 
angiogenic factors, cytokine receptors, and adhesion molecules, mediated by MMPs, ${ }^{5}$ have been suggested to contribute to this process. Tumorigenesis experiments have proposed that vascular endothelial growth factor (VEGF) may be released from the ECM by gelatinase $\mathrm{B}$ (MMP-9) and result in the angiogenic switch. ${ }^{5}$ Other in vitro studies have suggested that VEGF mediates its angiogenic effects by up-regulation of MMPs. ${ }^{16,17}$ In an effort to determine the interplay between VEGF and MMPs in the mediation of angiogenesis and to ascertain if MMPs act upstream or downstream of VEGF, we investigated the induction of angiogenesis in vivo by recombinant active MMPs and VEGF and the potential inhibitory activities of their respective inhibitors.

\section{Materials and Methods}

\section{Animals}

All animal studies were conducted in accordance with the Animal Care and Use Committee guidelines of the Cleveland Clinic and the ARVO Statement for the Use of Animals in Ophthalmic and Vision Research. Sprague Dawley rats (Harlan Laboratories, Indianapolis, IN) and

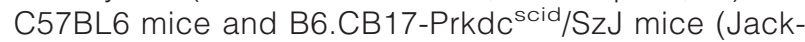
son Laboratories, Bar Harbor, ME) were used for these studies.

\section{Corneal Micropocket Assay}

Hydron pellets containing active MMP-9 (aMMP-9) (100 ng), pro-MMP-9 (pMMP-9) (100 ng), activeMMP-2 (aMMP-2) (100 ng), pro-MMP-2 (pMMP-2) (100 ng) (Calbiochem, San Diego, CA), buffer, or recombinant humanVEGF165 (kindly provided by Genentech, San Francisco, $\mathrm{CA}$ ), with or without neutralizing antibodies (monoclonal mouse anti-human VEGF, $1.5 \mu \mathrm{g}$ (R\&D systems, Minneapolis, MN) or MMP2/9 inhibitor (2R)-[4-biphenylylsulfonylamino]-N-hydroxy-3-phenylpropionamide, $2 \mu \mathrm{g}$, (Calbiochem) were inserted into corneal micropockets $(1 \mathrm{~mm}$ from the limbus) of Sprague-Dawley rats or C57 BL6 mice. Control mouse IgG, $1.5 \mu \mathrm{g}$ (Southern Biotechnology Inc., Birmingham, AL) antibodies were used in control pellets for comparison with anti-VEGF antibodies. Corneas were examined daily with the aid of a surgical microscope to monitor angiogenic responses to activated MMPs and VEGF. To photograph the angiogenic response, animals were perfused with India ink to label the vessels, and following enucleation and fixation, the corneas were excised, flattened, and photographed. A positive neovascularization response was recorded only if sustained directional in-growth of capillary sprouts and hairpin loops toward the pellet was observed. A negative response was recorded when either no growth was observed or only an occasional sprout or hairpin loop showing no evidence of sustained growth was detected. All responses were compared with a negative control (pellet containing buffer) and positive control (VEGF or aMMP). For neutralization studies, responses were compared with a negative control of nonspecific mouse immuno- globulin. Angiogenic response was analyzed for mean vascular extension and total skeletal (vascular) length using Image-Pro Plus 6.1 (Media Cybernetics, Silver Spring, MD). Before performing vessel measurements images were processed using best-fit equalization filters, spectral filters, and large pixel-width background removal filters to enhance vasculature and eliminate image artifacts. For total skeletal length measurements, processed images were skeletonized, summing pixel lengths of resultant skeletal segments. To determine mean vessel extension, processed images were thresholded for vasculature, filling in holes between adjacent vessels using morphological filters. The resulting image, a single segmented object representing the overall dimensions of the vascular bed, was analyzed for maximum box height, ie, extent of vessel penetration. Vessel area was calculated using the formula $\mathrm{VA}=0.02[\pi] \times \mathrm{VL} \times \mathrm{CH}$ where $\mathrm{VA}$ is the vessel area $\left(\mathrm{mm}^{2}\right), \mathrm{VL}$ is the vessel length, and $\mathrm{CH}$ is the clock hour as described previously. ${ }^{18}$

\section{In Situ Zymography}

Unfixed frozen cornea sections were quickly dried on microslides and overlaid with a solution containing 0.1 $\mathrm{mg} / \mathrm{ml}$ fluorescein-conjugated DQ gelatin (Molecular Probes, Carlsbad, CA) in phosphate-buffered saline (PBS). Parallel sections were overlaid with unconjugated gelatin as a negative control. The overlaid sections were incubated (1 hour at room temperature) in the dark, mounted in Vectashield with 4,6-diamidino-2-phenylindole and photographed using an Olympus fluorescent microscope.

\section{Immunohistochemistry}

Immunohistochemistry was performed on fresh frozen sections of mouse cornea per standard protocols. Briefly, sections were stained with primary rat anti-mouse CD11b (BD PharMingen, San Jose, CA) antibody at room temperature for 90 minutes followed by goat anti-rat IgG (Alexa Fluor 488, Invitrogen, San Diego, CA) as a secondary antibody or primary rabbit polyclonal VEGF (147) antibody (Santa Cruz Biotechnology, Santa Cruz, CA) at $4^{\circ} \mathrm{C}$ overnight followed by goat anti-rabbit IgG (Alexa Fluor 568, Invitrogen, San Diego, CA). After washing the sections were mounted in Vectashield with 4,6-diamidino-2phenylindole and visualized using an Olympus fluorescence microscope. Specificity of antibody staining was determined by comparison with nonspecific control IgG.

\section{Cell Migration Assay}

A modified Boyden chamber assay was performed as described previously. ${ }^{12}$ Polyvinylpyrrolidone free polycarbonate (PVPF) membranes, $8.0 \mu \mathrm{m}$ pore size, were precoated with collagen type I (100 $\mu \mathrm{g} / \mathrm{ml})$. Human dermal microvascular endothelial cells (Clonetics, San Diego, CA) $\left(3.0 \times 10^{5}\right)$ were placed in the upper wells and allowed to migrate toward activated MMPs placed in the lower wells. Chambers were incubated for 4 hours at $37^{\circ} \mathrm{C}$ in a $5 \% \mathrm{CO}_{2}$ humidified incubator. Cells remaining 
on the top of the filter were removed. The bottom surface of the filter was fixed, stained, and mounted. The number of cells migrating per well was counted microscopically and SEM was calculated from quadruplicate samples.

\section{Zymography}

Equal amounts of protein extracted from rat corneas were loaded on a $7.5 \%$ polyacrylamide gel with $1 \mathrm{mg} / \mathrm{ml}$ gelatin for zymography. Following electrophoresis, gels were processed as described previously. ${ }^{12}$ Briefly, gels were bathed in a solution of $25 \mathrm{mg} / \mathrm{ml}$ Triton $X-100$ to remove sodium dodecyl sulfate and to promote renaturation of proteases and inhibitors. The Triton was washed off with water and the gels incubated for 16 hours in 50 $\mathrm{mmol} / \mathrm{L} \mathrm{Tris-} \mathrm{HCl}\left(\mathrm{pH}\right.$ 7.5) containing $5 \mathrm{mmol} / \mathrm{L} \mathrm{CaCl}_{2}$ and $0.2 \mathrm{mg} / \mathrm{ml}$ sodium azide at $37^{\circ} \mathrm{C}$. Gels were stained with $5 \mathrm{mg} / \mathrm{ml}$ Coomassie Blue R-250 in acetic acid/methanol/ water (1:3:6) for 2 hours and destained with acetic acid/ methanol/water (1:3:6).

\section{$\left[{ }^{125}\right.$ /]VEGF Binding and Release from ECM}

RPE (ARPE-19) cells were plated onto 24-well culture plates. When confluent, the cells were removed from the culture dishes following a 15-minute incubation in $\mathrm{Ca}^{2+}{ }_{-}$, $\mathrm{Mg}^{2+}$-free PBS containing $5 \mathrm{mmol} / \mathrm{L}$ ethylene glycol bis ( $\beta$-aminoethyl ether)- $N, N, N^{\prime}, N^{\prime}$-tetraacetic acid and 1 $\mathrm{mmol} / \mathrm{L}$ phenylmethylsulfonyl fluoride. Several rinses with PBS and water and visual confirmation under a microscope ensured that the ECM on the dish was devoid of cells. The
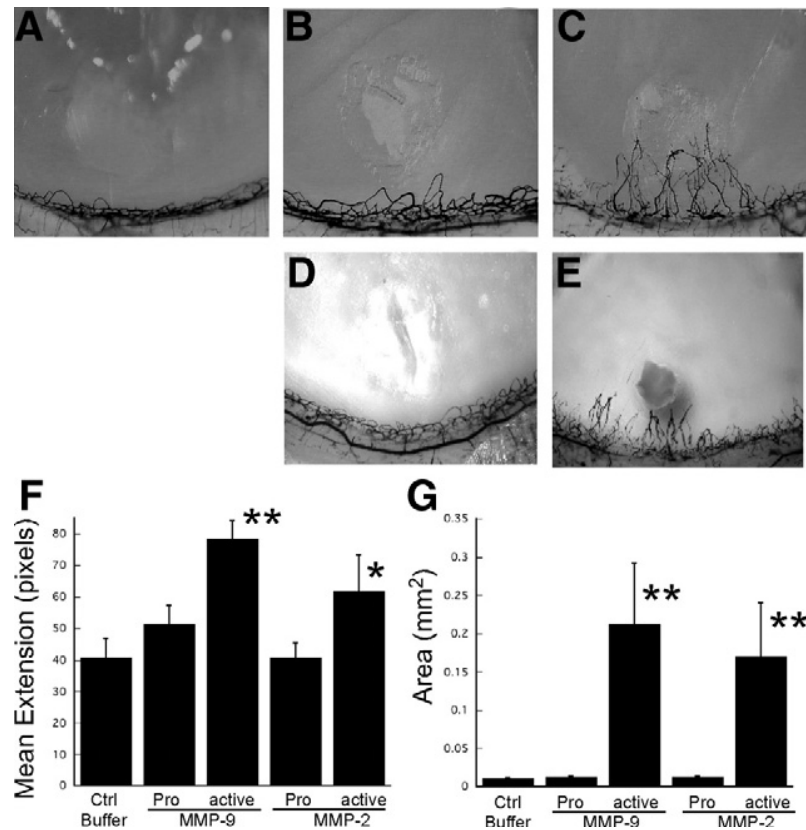

$\mathbf{G}_{\text {on }}$

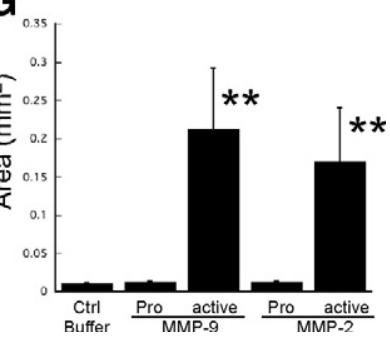

Figure 1. Active MMP-2 and MMP-9 induces angiogenesis in a rat corneal micropocket assay. Representative photographs of rat corneas ( $n \geq 5$ for each treatment) at 7 days after implantation of pellets containing buffer (control, A), pro-MMP-9 (100 ng, B), active MMP-9 (100 ng, C), pro-MMP-2 $(100 \mathrm{ng}, \mathbf{D})$, and active MMP-2 (E). Mean vessel extension $(\mathbf{F})$ and area $\left(\mathrm{mm}^{2}\right.$ G) were calculated as described in Materials and Methods. ${ }^{* *} P=0.003,{ }^{*} P=$ 0.008 .
ECM was incubated with $1.5 \mu \mathrm{Ci} / \mathrm{ml}\left[{ }^{125}\right] \mathrm{VEGF}_{165}$ (specific activity, $1805 \mathrm{Ci} / \mathrm{mmol}$, Amersham, Piscataway, NJ) for 2 hours at room temperature. After extensive washing to remove unbound VEGF, the ECM preparations were incubated with $3.5 \mathrm{nmol} / \mathrm{L}$ of active MMP-2 or MMP-9 for 18 hours at $37^{\circ} \mathrm{C}$. At the end of the experiment the ECM proteins were solubilized with lysis buffer $(20 \mathrm{mmol} / \mathrm{L}$ Tris- $\mathrm{HCl}$ $\mathrm{pH} 7.5,1 \%$ Triton $\mathrm{X}-100,10 \%$ glycerol), and the radioactivity measured in a gamma counter. Protein concentrations were estimated using the Bio-Rad protein assay reagent (Bio-Rad Laboratories, Hercules, CA).

\section{Statistical Analysis}

Data are presented as mean \pm SEM. The statistical significance of differential findings observed between experimental and control groups was determined using Student's t-test or one-way analysis of variance and considered to be significant if $P$ values were $<0.05$.

\section{Results}

\section{Induction of Corneal Neovascularization by the Active Form of Gelatinases (MMP-2 and MMP-9)}

To determine the ability of aMMPs to induce corneal neovascularization in vivo, micropellets of the slow re-
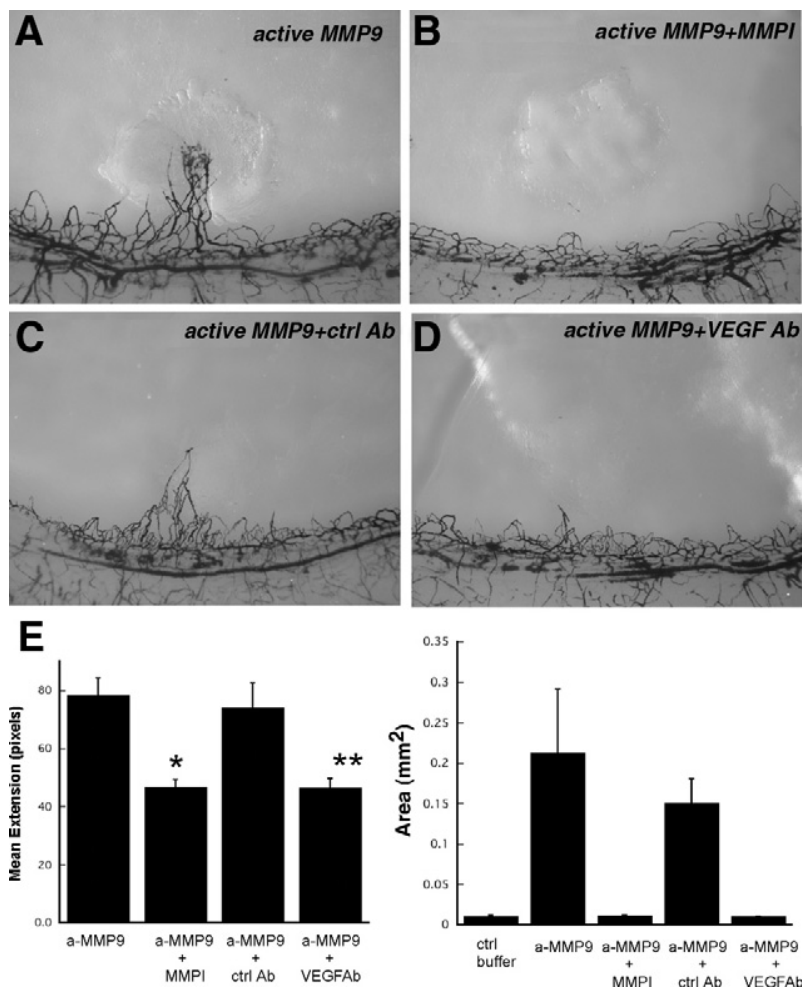

Figure 2. Neutralization of MMP-9 induced angiogenesis by monoclonal anti-VEGF antibody. Representative photographs of rat corneas ( $n \geq 5$ for each treatment) at 7 days following implantation of pellets containing active MMP-9 (100 ng, A), active MMP-9 (100 ng) with MMP inhibitor (2 $\mu \mathrm{g}, \mathbf{B})$, active MMP-9 (100 ng) with nonspecific control $\operatorname{IgG}(1.5 \mu \mathrm{g}, \mathbf{C})$, and active MMP-9 (100 ng) with anti-VEGF neutralizing antibody $(1.5 \mathrm{~g}, \mathbf{D})$. E: Mean vessel extension and area $\left(\mathrm{mm}^{2}\right)$ were calculated as described in Materials and Methods. ${ }^{*} P=0.005,{ }^{* *} P=0.001,{ }^{* * * *} P<0.0001$. 
lease polymer-hydron containing recombinant active MMP-9 (100 ng) or active MMP-2 (100 ng) were implanted into the corneas of female Harlan Sprague Dawley rats. The implanted corneas were analyzed for induction of angiogenesis following India ink perfusion at day 7. Pellets containing active MMP-9 or MMP-2 stimulated corneal neovascularization that peaked at day 7 with a mean extension length of $78.3 \pm 5.8$ pixels (Figure 1, C and $F$ ) or $62.02 \pm 11.2$ (Figure $1, E$ and $F$ ) respectively. In comparison, pellets containing the recombinant pro- form of MMP-9 (100 ng) (Figure 1B), pro- form of MMP-2 (100 ng) (Figure 1D), or buffer alone (Figure 1A) evoked a minimal response, $48.7 \pm 6.3,40.8 \pm 4.5$, and $36.5 \pm 2.1$ pixels, respectively (Figure 1F). Only the active forms of MMP-9 and MMP-2 induced circumferential neovascularization measured in square millimeter area (Figure 1G).
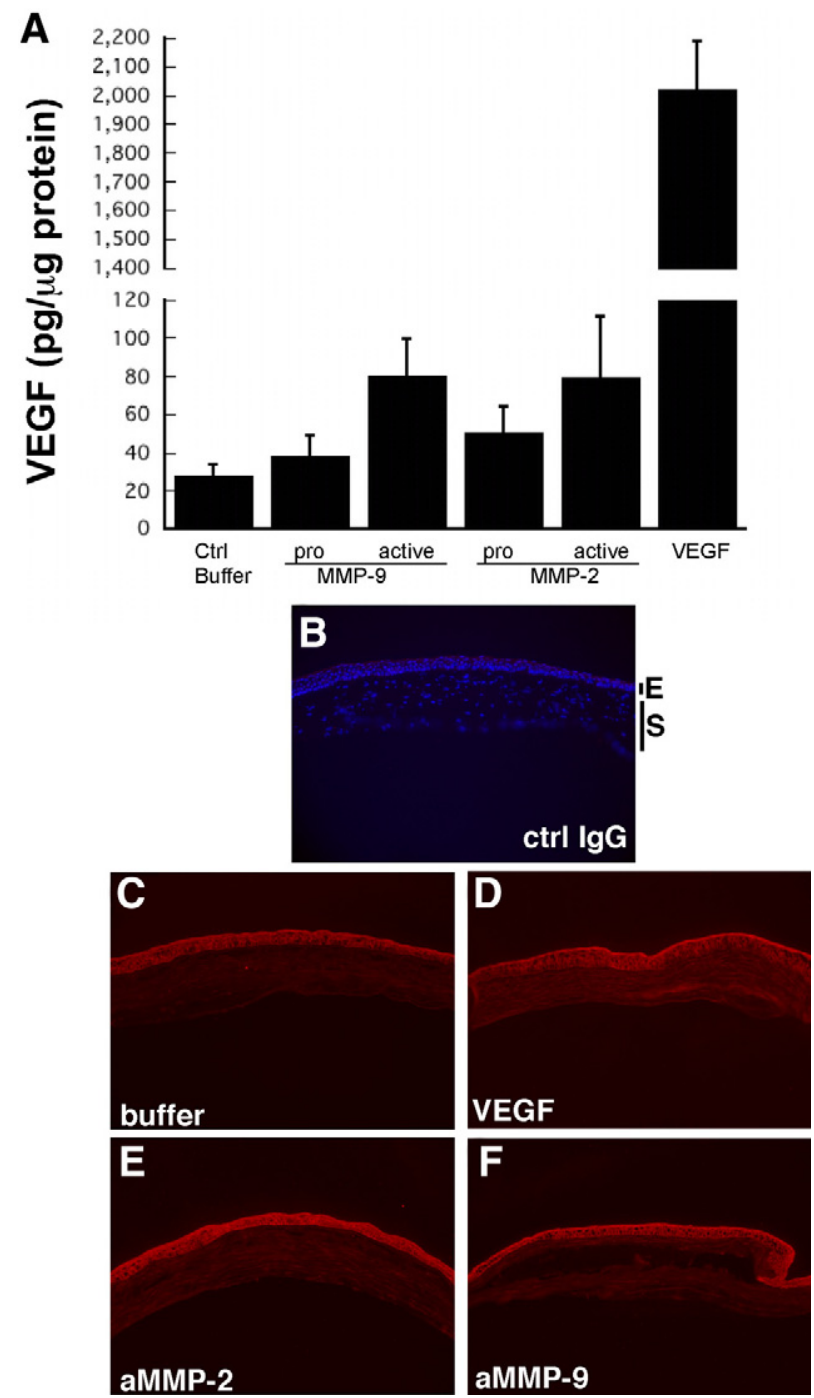

Figure 3. Increased VEGF expression in corneas implanted with pellets containing active MMP-9 and MMP-2. VEGF levels in corneas implanted with pellets containing active MMPs were analyzed by enzyme-linked immunosorbent assay (A) and expressed as picograms of VEGF per microgram of total protein. Immunohistochemical localization of VEGF protein in corneas 24 hours following implantation with control buffer (C), VEGF (D), active MMP-2 (E), and active MMP-9 (F). Representative image of cornea implanted with control buffer and stained with a nonspecific control IgG (B) to determine specificity of staining.

\section{Active MMP-9 Induces Corneal \\ Neovascularization via the VEGF Pathway}

In an effort to determine whether the induction of angiogenesis by active MMP-9 occurs via the VEGF pathway, micropellets containing active MMP-9 with or without neutralizing VEGF antibody $(1.5 \mu \mathrm{g})$ were implanted into rat corneas and analyzed by India ink perfusion (Figure 2, A, C, D). Neutralizing VEGF antibody almost completely inhibited the aMMP-9 induced angiogenic response when analyzed for mean skeletal extension as well as area of neovascularization (Figure 2, D and E). The inhibitory response with VEGF antibody was similar to that obtained with a synthetic MMP-9 inhibitor (Figure 2, B and E). Mean skeletal extension with aMMP-9 was decreased to $46.9 \pm 5.7$ pixels in the presence of VEGF antibody when compared with $74.4 \pm 7.9$ pixels with a nonspecific control antibody (Figure 2). Similar results were obtained on analysis of circumferential neovascularization measured as square millimeter area with inhibition observed with MMP inhibitors and specific antiVEGF antibody (Figure 2F). To determine whether VEGF levels were increased by active MMPs, we analyzed the rat corneas at day 5 following pellet implantation. VEGF levels were increased in corneas implanted with pellets containing active MMPs when analyzed by enzymelinked immunosorbent assay (Figure 3A). Immunohistochemical analyses of the corneas implanted with control IgG (Figure 3C) control buffer (Figure 3D), VEGF (Figure 3C), aMMP-2 (Figure 3E), and aMMP-9 (Figure 3F) pellets determined that VEGF secretion in response to active MMPs occurred as early as 24 hours following implantation and was localized around the epithelial cell layer with modest expression in the stromal layer.

\section{Activated MMPs Can Release VEGF from the Extracellular Matrix and Directly Induce Endothelial Cell Migration}

Incubation of ECM preparations with [ ${ }^{125}$ I]VEGF for 2 hours resulted in a binding of VEGF to the ECM. Following extensive washing with PBS to remove unbound growth

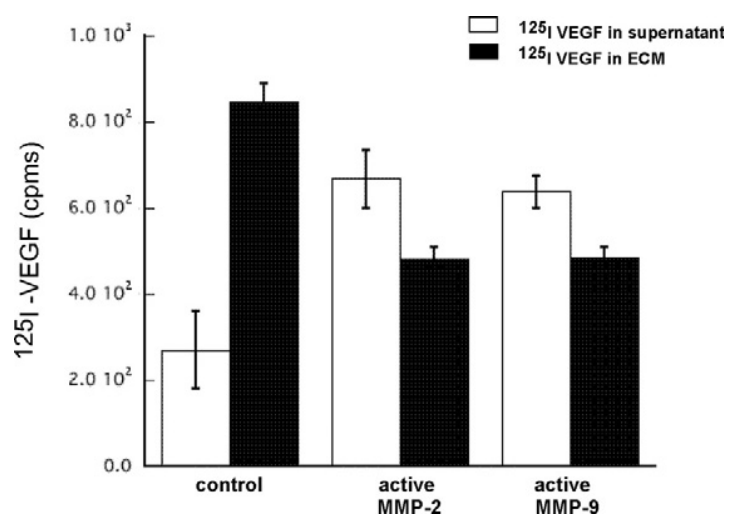

Figure 4. Active MMPs can release VEGF sequestered in the extracellular matrix. ECM preparations containing sequestered $\left[{ }^{125} \mathrm{I}\right]$ VEGF were treated with active MMP-2 and active MMP-9 for 18 hours. Supernatant and ECM fractions were analyzed for $\left[{ }^{125} \mathrm{I}\right]$ VEGF counts per minute. 


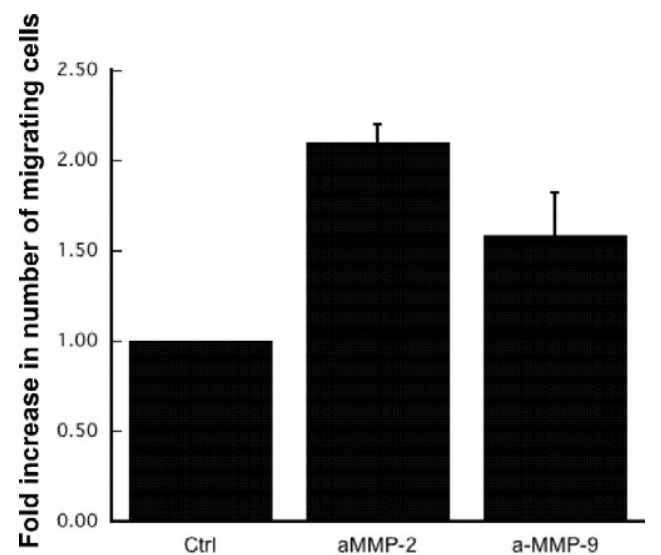

Figure 5. Active MMPs can induce endothelial cell migration. The ability of active MMP-2 and MMP-9 to induce endothelial cell chemotaxis was examined using a modified Boyden chamber assay. Migrating cell number is expressed as fold increase in number of cells migrating toward control buffer \pm SEM of quadruplicate samples. All experiments were done in triplicate.

factor, the ECM-VEGF preparations were incubated in PBS containing aMMP-2 or aMMP-9 for 18 hours. Supernatant and ECM fractions were analyzed for $\left[{ }^{125}\right.$ I]VEGF counts per minute. Active forms of both MMP-2 and MMP-9 could release bound VEGF from the ECM into the supernatant (Figure 4). Activated MMPs were also examined for their ability to directly induce capillary endothelial
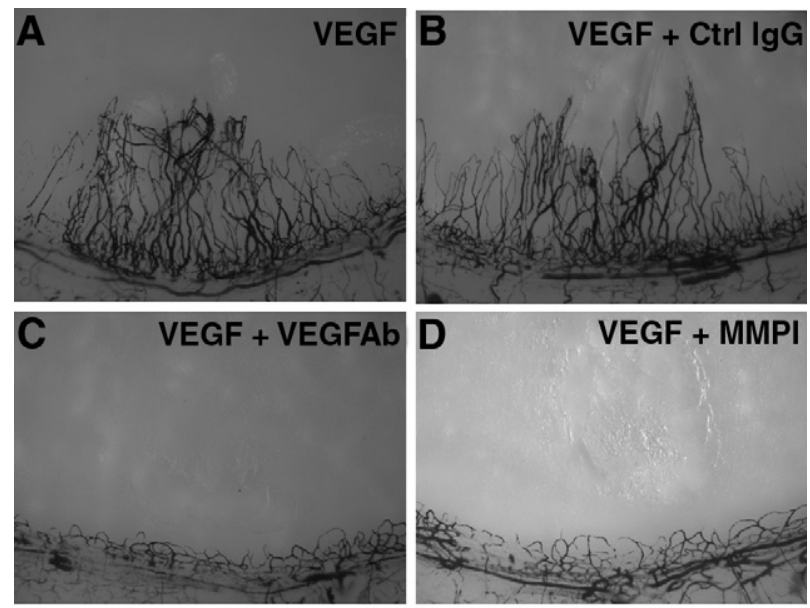

E

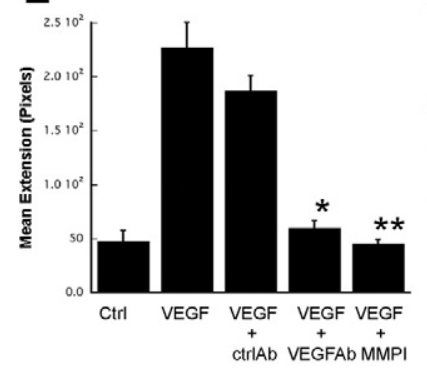

$\mathbf{F}$

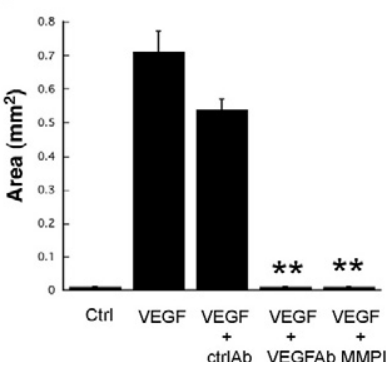

Figure 6. Neutralization of VEGF induced angiogenesis by MMP inhibitor. Representative photographs of rat corneas ( $n \geq 4$ for each treatment) at 7 days following implantation of pellets containing VEGF (50 ng, A), VEGF (50 ng) with nonspecific control IgG (1.5 $\mu \mathrm{g}, \mathbf{B})$, VEGF (50 ng) with anti-VEGF neutralizing antibody $(1.5 \mu \mathrm{g}, \mathbf{C})$, and VEGF $(50 \mathrm{ng})$ with MMP inhibitor $(2 \mu \mathrm{g}, \mathbf{D})$. Mean vessel extension $(\mathbf{E})$ and area $\left(\mathrm{mm}^{2}, \mathbf{F}\right)$ were calculated as described in Materials and Methods. ${ }^{*} P=0.0004,{ }^{* * *} P<0.0001$.
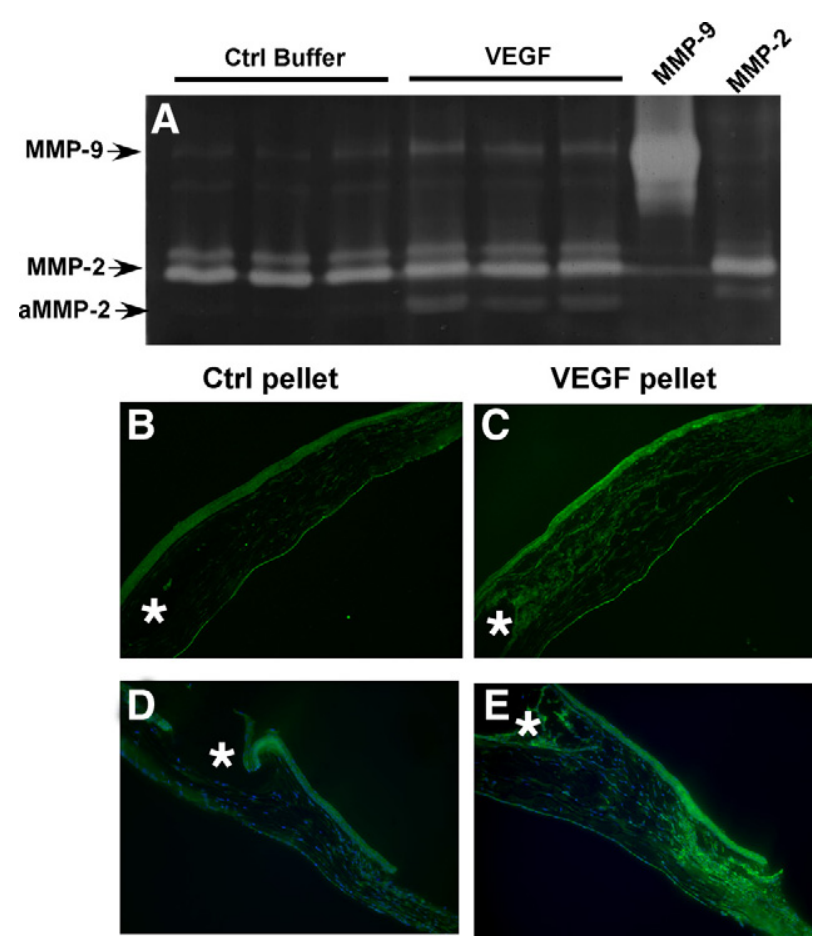

Figure 7. Increased MMP-2 and MMP-9 expression in corneas implanted with pellets containing VEGF. MMP-2 and MMP-9 levels in three corneas implanted with pellets containing VEGF or control buffer were analyzed by zymography (A). In situ zymography analysis of corneas 24 hours following implantation with control pellets $(\mathbf{B}, \mathbf{D})$ and VEGF pellets $(\mathbf{C}, \mathbf{E})$. Asterisks indicate the location of pellets.

cell migration using a modified Boyden chamber assay. Activated MMP-2 and MMP-9 stimulated an approximately twofold increase in migratory response in endothelial cells with a maximum effect at doses of $10 \mathrm{ng} / \mathrm{ml}$ and $30 \mathrm{ng} / \mathrm{ml}$ respectively (Figure 5 ).

\section{VEGF-Induced Corneal Neovascularization Is Mediated via Matrix Metalloproteinases}

To determine whether VEGF-mediated corneal neovascularization was mediated via MMPs, micropellets of the slow release polymer-hydron containing recombinant VEGF with and without MMP inhibitor were implanted into the corneas of rats. VEGF induced a marked angiogenic response with a mean limbal vessel skeletal extension of $251 \pm 31.1$ pixels (Figure 6, A, E, F), which could be inhibited to background levels by VEGF antibody (46.3 \pm 4.6 pixels) (Figure $6 \mathrm{C}$ ) and MMP inhibitor (42.6 \pm 5.4 pixels) (Figure 6D). Control nonspecific antibody had no effect on the VEGF induced neovascularization response (Figure 6B). Rat corneas implanted with VEGF containing pellets were analyzed for MMPs by zymography at day 4 following implantation. Pellets containing VEGF induced activation of both MMP-2 and MMP-9 (Figure 7A) when compared with corneas containing control pellets. In situ zymography revealed that most of the active gelatinase activity was localized in the stroma as early as 24 hours following pellet implantation (Figure 7, B-D). 

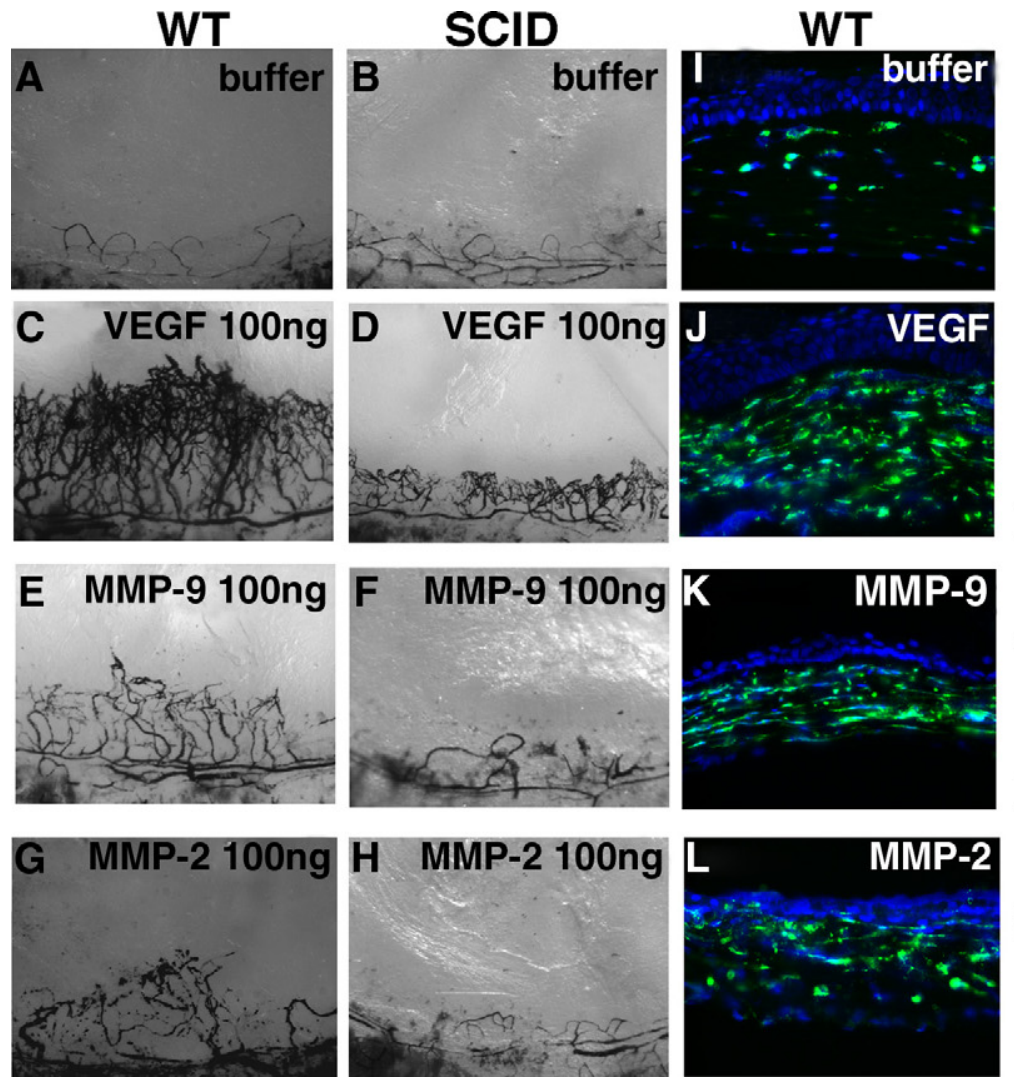

Figure 8. VEGF- and active MMP-induced corneal neovascularization is mediated by inflammatory cells. Representative photographs of mouse corneas ( $n=4$ for each pellet) at 7 days following implantation of pellets in wild-type (WT) mice containing buffer (A), VEGF (100 ng, C), active MMP-9 (100 ng, E), active MMP-2 (100 ng, G), and in SCID mice containing buffer (B), VEGF (100 ng, D), active MMP-9 (100 ng, F), and active MMP-2 (100 ng, H). Immunohistochemical staining of CD11b in corneas of wild-type mice 24 hours following implantation with buffer (I), VEGF (50 ng, J), active MMP-9 (100 ng, K), and active MMP-2 (100 ng, L). M: Mean vessel extension was calculated as described in Materials and Methods. ${ }^{* * *} P=0.06,{ }^{*} P<0.005$.

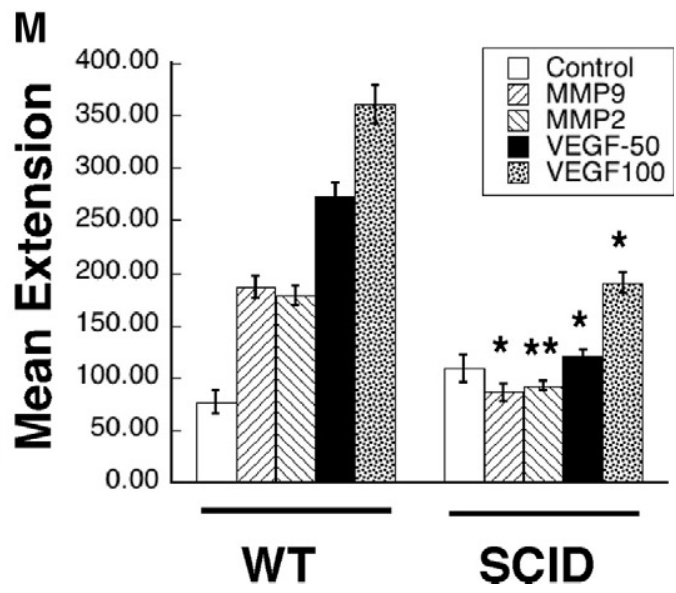

\section{MMP and VEGF-Mediated Corneal \\ Neovascularization Is Attenuated in Immune Deficient Mice}

Both MMP and VEGF mediated corneal neovasculariza-

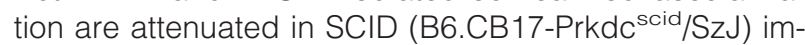
mune deficient mice (Figure $8, B, D, F, H, M$ ) when compared with wild-type mice (Figure 8, A, C, E, G, M). The influx of CD11b inflammatory cells into the corneal stroma was examined by immunohistochemistry and was found to be increased 24 hours following VEGF (Figure 8, $\mathrm{I}$ and J), active MMP-2 (Figure 8K) and active MMP-9 (Figure 8K) pellet implantation.

\section{Discussion}

Developmental vascular patterning, as well as pathological neovascularization is orchestrated by specific temporal and spatial signals that result in the degradation of the vascular basement membrane and remodeling of the ECM to enable endothelial cells to migrate into the surrounding tissue. MMPs (matrixins) are a multiple gene family of zinc-dependent endopeptidases that can collectively degrade all known ECM macromolecules and have been postulated to play a critical step in the initiation of new vessel sprouting. Notwithstanding the large body of evidence that suggest a proangiogenic role for MMPs, the detailed mechanisms by which these enzymes function in this capacity are unclear. One hypothesis that has been proposed is that MMP-9/gelatinase B can increase the availability of the angiogenesis inducer VEGF. ${ }^{5}$ More recently, MMP-9 has been shown to be important in mobilizing endothelial and other progenitor cells from the bone marrow niche ${ }^{19}$ as well as modulating tumor neovascularization when delivered by proangiogenic bone marrow-derived cells. ${ }^{20,21}$ Other evidence also suggests that VEGF can induce the activation of gelatinases in retinal pigment epithelial cells. ${ }^{22,23}$ While some evidence exists about the interplay between MMPs and VEGF, ${ }^{24}$ much of the data has been generated using in vitro models or a variety of tumor models to address specific aspects of the role of MMPs and VEGF in neovascularization.

To directly assess the presence of cross talk between gelatinases and VEGF we opted to use the rat corneal micropocket assay using sustained release VEGF-hydron pellets due to its predictable and consistent neovascular response that is independent of the induction of inflammation. ${ }^{25}$ Most studies have concluded that MMPs play an important role in angiogenesis by virtue of their being up-regulated during the process of angiogenesis, ${ }^{26-29}$ or by the fact that inhibition of MMPs (either by MMP inhibitors ${ }^{15,30-32}$ or in MMP deficient mice ${ }^{11,33,34}$ results in an inhibition of angiogenesis using a multitude of neovascularization models. To our knowledge this is the first study demonstrating the ability of recombinant active MMPs to directly induce angiogenesis in vivo. In addition, the ability of neutralizing VEGF antibodies to completely block the angiogenic effect of active MMPs suggests the VEGF pathway to be critical in this response. We have also 
demonstrated the ability of active MMP-2 and MMP-9 to release bound VEGF from ECM preparations. Given that this occurs in vitro in the absence of cells, lends credence to the hypothesis suggested previously that VEGF is sequestered in the ECM and is released and made available to act on endothelial cells by active gelatinases. Additionally, VEGF has been shown to be cleaved intramolecularly by a subset of MMPs resulting in the release of a receptor-binding domain from the ECM binding motif of VEGF-A isoforms. ${ }^{35}$ Release of soluble VEGF isoforms induces dilated large vasculature, whereas the MMP-resistant forms lead to excessive and disorganized branching. ${ }^{35}$ MMP dependent proteolytic cleavage of VEGF has also been shown to be important in the establishment of growth factor gradients that are critical for endothelial tip cell guidance as well as stalk cell proliferation and regulate physiological as well as pathological neovascularization in the retina. ${ }^{36}$

On the other hand, our results also determine that VEGF induced neovascularization is MMP dependent as it can be inhibited by synthetic MMP inhibitors. Recently, cross-talk between VEGF and MMP-9 has been suggested to play a role in ovarian carcinoma invasion and metastasis. $^{37-40}$ Host cells, specifically inflammatory cells as opposed to tumor cells, have been implicated as being the primary source of MMP-9 in these models. ${ }^{37}$ Previous studies have determined that VEGF-mediated inflammation plays a critical role in the pathological angiogenesis induced by it. ${ }^{41-43}$ Our results suggest that both VEGF and active MMPs recruit CD11b + inflammatory cells to the corneal stroma, which are likely to play a critical role in the angiogenic response. Whether these inflammatory cells are recruited from the bone marrow or locally from the cornea remains to be determined. In addition, our results support the hypothesis that the spatial localization of MMPs in a tumor microenvironment regulates the localized release of VEGF. ${ }^{44}$ In the corneal neovascularization model VEGF induces the up-regulation of active MMPs primarily in the stroma, while active MMPs result in an increased expression of VEGF in the epithelial layer. While our in vitro studies suggest that MMPs can induce VEGF to be released from the extracellular matrix in the absence of cells, we cannot rule out VEGF being secreted by the epithelium, stromal keratocytes, fibroblasts, and/or inflammatory cells. The Phase III clinical trials with second-generation small molecules as well as peptidomimic-based MMP inhibitor drugs did not result in increased survival. ${ }^{45-47}$ However, this could be a result of using broad-spectrum MMP inhibitors that were pro and anti-tumorigenic. ${ }^{48} \mathrm{~A}$ more detailed understanding of the unique pathways used by specific MMPs during tumor progression is essential to characterize the role played by proteases in this disease process. Our results suggest that MMPs act both upstream as well as downstream of VEGF and that combination therapy of VEGF inhibitors with MMP inhibitors given in a temporally restricted fashion may be useful in the treatments of cancers and other diseases with pathological neovascularization.

\section{References}

1. Pepper MS, Montesano R, Mandriota SJ, Orci L, Vassalli JD: Angiogenesis: a paradigm for balanced extracellular proteolysis during cell migration and morphogenesis. Enzyme Protein 1996, 49:138-162

2. Somerville RP, Oblander SA, Apte SS: Matrix metalloproteinases: old dogs with new tricks. Genome Biol 2003, 4:216

3. Matrisian LM: The matrix degrading metalloproteinases. Bioessays 1992, 14:455-463

4. Nagase H, Woessner JF, Jr.: Matrix metalloproteinases. J Biol Chem 1999, 274:21491-21494

5. Bergers G, Brekken R, McMahon G, Vu TH, Itoh T, Tamaki K, Tanzawa K, Thorpe P, Itohara S, Werb Z, Hanahan D: Matrix metalloproteinase-9 triggers the angiogenic switch during carcinogenesis. Nat Cell Biol 2000, 2:737-744

6. Chang C, Werb Z: The many faces of metalloproteases: cell growth invasion, angiogenesis and metastasis. Trends Cell Biol 2001, 11:S37-S43

7. Hiraoka N, Allen E, Apel IJ, Gyetko MR, Weiss SJ: Matrix metalloproteinases regulate neovascularization by acting as pericellular fibrinolysins. Cell 1998, 95:365-377

8. Stetler-Stevenson WG: The role of matrix metalloproteinases in tumor invasion, metastasis, and angiogenesis. Surg Oncol Clin N Am 2001, 10:383-392

9. Itoh $\mathrm{T}$, Tanioka M, Yoshida $\mathrm{H}$, Yoshioka $\mathrm{T}$, Nishimoto $\mathrm{H}$, Itohara S: Reduced angiogenesis and tumor progression in gelatinase A-deficient mice. Cancer Res 1998, 58:1048-1051

10. Vu TH, Shipley JM, Bergers G, Berger JE, Helms JA, Hanahan D, Shapiro SD, Senior RM, Werb Z: MMP-9/gelatinase B is a key regulator of growth plate angiogenesis and apoptosis of hypertrophic chondrocytes. Cell 1998, 93:411-422

11. Zhou Z, Apte SS, Soininen R, Cao R, Baaklini GY, Rauser RW, Wang J, Cao Y, Tryggvason K: Impaired endochondral ossification and angiogenesis in mice deficient in membrane-type matrix metalloproteinase I. Proc Natl Acad Sci USA 2000, 97:4052-4057

12. Qi JH, Ebrahem Q, Moore N, Murphy G, Claesson-Welsh L, Bond M, Baker A, Anand-Apte B: A novel function for tissue inhibitor of metalloproteinases-3 (TIMP3): inhibition of angiogenesis by blockage of VEGF binding to VEGF receptor-2. Nat Med 2003, 9:407-415

13. Seo DW, Li H, Guedez L, Wingfield PT, Diaz T, Salloum R, Wei BY, Stetler-Stevenson WG: TIMP-2 mediated inhibition of angiogenesis: an MMP-independent mechanism. Cell 2003, 114:171-180

14. Lafleur MA, Handsley MM, Edwards DR: Metalloproteinases and their inhibitors in angiogenesis. Expert Rev Mol Med 2003, 5:1-39

15. Rundhaug JE: Matrix metalloproteinases and angiogenesis. J Cell Mol Med 2005, 9:267-285

16. Lamoreaux WJ, Fitzgerald ME, Reiner A, Hasty KA, Charles ST: Vascular endothelial growth factor increases release of gelatinase $A$ and decreases release of tissue inhibitor of metalloproteinases by microvascular endothelial cells in vitro. Microvasc Res 1998, 55:29-42

17. Wang $\mathrm{H}$, Keiser JA: Vascular endothelial growth factor upregulates the expression of matrix metalloproteinases in vascular smooth muscle cells: role of flt-1. Circ Res 1998, 83: 832-840

18. Rogers MS, Birsner AE, D'Amato RJ: The mouse cornea micropocket angiogenesis assay. Nat Protoc 2007, 2:2545-2550

19. Heissig B, Hattori K, Dias S, Friedrich M, Ferris B, Hackett NR, Crystal RG, Besmer P, Lyden D, Moore MA, Werb Z, Rafii S: Recruitment of stem and progenitor cells from the bone marrow niche requires MMP-9 mediated release of kit-ligand. Cell 2002, 109:625-637

20. Ahn GO, Brown JM: Matrix metalloproteinase-9 is required for tumor vasculogenesis but not for angiogenesis: role of bone marrow-derived myelomonocytic cells. Cancer Cell 2008, 13:193-205

21. Du R, Lu KV, Petritsch C, Liu P, Ganss R, Passegue E, Song H, Vandenberg S, Johnson RS, Werb Z, Bergers G: HIF1alpha induces the recruitment of bone marrow-derived vascular modulatory cells to regulate tumor angiogenesis and invasion. Cancer Cell 2008, 13:206-220

22. Hoffmann S, Masood R, Zhang Y, He S, Ryan SJ, Gill P, Hinton DR: Selective killing of RPE with a vascular endothelial growth factor chimeric toxin. Invest Ophthalmol Vis Sci 2000, 41:2389-2393

23. Pepper MS: Extracellular proteolysis and angiogenesis. Thromb Haemost 2001, 86:346-355

24. Hollborn M, Stathopoulos C, Steffen A, Wiedemann P, Kohen L, 
Bringmann A: Positive feedback regulation between MMP-9 and VEGF in human RPE cells. Invest Ophthalmol Vis Sci 2007, 48:4360-4367

25. Kenyon B, Voest E, Chen C, Flynn E, Folkman J, D'Amato R: A model of angiogenesis in the mouse cornea. Invest Ophthalmol Vis Sci 1996 , 37:1625-1632

26. Hoffmann S, He S, Ehren M, Ryan SJ, Wiedemann P, Hinton DR: MMP-2 and MMP-9 secretion by rpe is stimulated by angiogenic molecules found in choroidal neovascular membranes. Retina 2006 26:454-461

27. Nguyen M, Arkell J, Jackson CJ: Active and tissue inhibitor of matrix metalloproteinase-free gelatinase B accumulates within human microvascular endothelial vesicles. J Biol Chem 1998, 273:5400-5404

28. Nguyen M, Arkell J, Jackson CJ: Human endothelial gelatinases and angiogenesis. Int J Biochem Cell Biol 2001, 33:960-970

29. Taraboletti G, D'Ascenzo S, Borsotti P, Giavazzi R, Pavan A, Dolo V: Shedding of the matrix metalloproteinases MMP-2, MMP-9, and MT1MMP as membrane vesicle-associated components by endothelial cells. Am J Pathol 2002, 160:673-680

30. Azar DT: Corneal angiogenic privilege: angiogenic and antiangiogenic factors in corneal avascularity, vasculogenesis, and wound healing (an American Ophthalmological Society thesis). Trans Am Ophthalmol Soc 2006, 104:264-302

31. Barnett JM, McCollum GW, Fowler JA, Duan JJ, Kay JD, Liu RQ, Bingaman DP, Penn JS: Pharmacologic and genetic manipulation of MMP-2 and -9 affects retinal neovascularization in rodent models of OIR. Invest Ophthalmol Vis Sci 2007, 48:907-915

32. Blackburn JS, Rhodes $\mathrm{CH}$, Coon $\mathrm{Cl}$, Brinckerhoff $\mathrm{CE}$ : RNA interference inhibition of matrix metalloproteinase-1 prevents melanoma metastasis by reducing tumor collagenase activity and angiogenesis. Cancer Res 2007, 67:10849-10858

33. Kato $\mathrm{T}$, Kure $\mathrm{T}$, Chang JH, Gabison EE, Itoh $\mathrm{T}$, Itohara S, Azar DT: Diminished corneal angiogenesis in gelatinase A-deficient mice. FEBS Lett 2001, 508:187-190

34. Lambert V, Munaut C, Jost M, Noel A, Werb Z, Foidart JM, Rakic JM: Matrix metalloproteinase-9 contributes to choroidal neovascularization. Am J Pathol 2002, 161:1247-1253

35. Lee S, Jilani SM, Nikolova GV, Carpizo D, Iruela-Arispe ML: Processing of VEGF-A by matrix metalloproteinases regulates bioavailability and vascular patterning in tumors. J Cell Biol 2005, 169:681-691

36. Lundkvist A, Lee S, Iruela-Arispe L, Betsholtz C, Gerhardt H: Growth factor gradients in vascular patterning. Novartis Found Symp 2007, 283:194-196, 238-141

37. Belotti D, Calcagno C, Garofalo A, Caronia D, Riccardi E, Giavazzi R,
Taraboletti G: Vascular endothelial growth factor stimulates organspecific host matrix metalloproteinase- 9 expression and ovarian cancer invasion. Mol Cancer Res 2008, 6:525-534

38. Belotti D, Paganoni P, Manenti L, Garofalo A, Marchini S, Taraboletti G, Giavazzi R: Matrix metalloproteinases (MMP9 and MMP2) induce the release of vascular endothelial growth factor (VEGF) by ovarian carcinoma cells: implications for ascites formation. Cancer Res 2003, 63:5224-5229

39. Yabushita $H$, Shimazu M, Noguchi M, Kishida T, Narumiya $H$, Sawaguchi K, Noguchi M: Vascular endothelial growth factor activating matrix metalloproteinase in ascitic fluid during peritoneal dissemination of ovarian cancer. Oncol Rep 2003, 10:89-95

40. Zhang A, Meng L, Wang Q, Xi L, Chen G, Wang S, Zhou J, Lu Y, Ma $D$ : Enhanced in vitro invasiveness of ovarian cancer cells through up-regulation of VEGF and induction of MMP-2. Oncol Rep 2006, 15:831-836

41. Croll SD, Ransohoff RM, Cai N, Zhang Q, Martin FJ, Wei T, Kasselman LJ, Kintner J, Murphy AJ, Yancopoulos GD, Wiegand SJ: VEGFmediated inflammation precedes angiogenesis in adult brain. Exp Neurol 2004, 187:388-402

42. Kasselman LJ, Kintner J, Sideris A, Pasnikowski E, Krellman JW, Shah S, Rudge JS, Yancopoulos GD, Wiegand SJ, Croll SD: Dexamethasone treatment and ICAM-1 deficiency impair VEGF-induced angiogenesis in adult brain. J Vasc Res 2007, 44:283-291

43. Proescholdt MA, Heiss JD, Walbridge S, Muhlhauser J, Capogrossi MC, Oldfield EH, Merrill MJ: Vascular endothelial growth factor (VEGF) modulates vascular permeability and inflammation in rat brain. J Neuropathol Exp Neurol 1999, 58:613-627

44. Mira E, Lacalle RA, Buesa JM, de Buitrago GG, Jimenez-Baranda S, Gomez-Mouton C, Martinez AC, Manes S: Secreted MMP9 promotes angiogenesis more efficiently than constitutive active MMP9 bound to the tumor cell surface. J Cell Sci 2004, 117:1847-1857

45. Coussens LM, Fingleton B, Matrisian LM: Matrix metalloproteinase inhibitors and cancer: trials and tribulations. Science 2002, 295: 2387-2392

46. Fingleton B: Matrix metalloproteinases as valid clinical targets. Curr Pharm Des 2007, 13:333-346

47. Overall CM, Lopez-Otin C: Strategies for MMP inhibition in cancer: innovations for the post-trial era. Nat Rev Cancer 2002, 2:657-672

48. Overall CM, Kleifeld O: Tumour microenvironment-opinion: validating matrix metalloproteinases as drug targets and anti-targets for cancer therapy. Nat Rev Cancer 2006, 6:227-239 